\title{
ДИПЛОМАТИЯ
}

А.Я. Нейматова

$10.7256 / 2305-560 X .2013 .01 .9$

\section{МИД РОССИИ И НОВАЯ ПУБЛИЧНАЯ ДИПЛОМАТИЯ}

\begin{abstract}
Аннотация. Современность порождает все новые и новые реалии. Одним из актуальных явлений наших дней является новая публичная дипломатия, предполагающая все более активную работу с общественным мнением и поддержанние с зарубежными целевыми аудиториями постоянного диалога. Такой формат общения невозможен без использования новых коммуникационных технологий. Россия только выходит на путь модернизации публичной дипломатии и использования социальных медиа. Автор рассматривает достижения и трудности, с которыми сталкивается российская дипломатия на данном поприще.
\end{abstract}

Ключевые слова: политология, международные отношения, внешняя политика, национальная безопасность, имидж государства, национальный брендинг, публичная дипломатия, Россия, МИД, иенности.

$\mathrm{H}$ овая публичная дипломатия — актуальное явление в мировой политике, активно изучаемое в теории и на практике на Западе. Важность и необходимость ее применения в российской практике диктует сама современность.

Новая публичная дипломатия, отвечающая всем тенденциям современности и, собственно, ею и порожденная, представляется одним из наиболее эффективных решений для формирования благоприятного международного имиджа страны.

О появлении такой категории, впервые заявил Профессор Гарвардского университета Джозеф С. Най мл. ${ }^{1}$ который в качестве особенности данного явления выделил переход от односторонней передачи информации к двустороннему диалогу. Как уже отмечалось, новая публичная дипломатия использует в своем арсенале последние коммуникационные технологии, и в ней самым активным образом участвуют негосударственные акторы.

Введение в оборот термина «новая публичная дипломатия» отражает кардинальные изменения в характере и формах подачи внешнеполитической информации со времен «холодной войны». Современные ученые, занимающиеся проблемами публичной дипломатии, (М. Леонард, К. Стед, К. Смевинг, Дж.С. Най $)^{2}$ придерживаются именно такой точки зрения, а именно, что новая публичная дипломатия -

Nye J.S. New Public Diplomacy [Electronic resource] / J.S. Nye. - Project Syndicate: a World of Ideas. Cambridge, 2010. - Режим доступа: http://www.project-syndicate.org/commentary/nye79/Russian. - Загл. с экрана.

2 Leonard M. Public Diplomacy / M. Leonard, C. Stead, C. Smewing. London, Foreign Policy Centre, 2002; Nye, J.S.Jr. Soft Power: The Means To Success In World Politics / J.S. Nye. PublicAffairs, 2005. это качественно новое явление, а не простой эвфемизм для всех знакомого слова «пропаганда», с которым их объединяет, по сути, только нацеленность на убеждение людей.

В течение многих столетий, говоря «дипломатия», первым делом на ум приходили переговоры, официальные отношения между государствами, обмен между ними официальными документами: нотами, грамотами и т.д. В принципе это и составляет основу традиционной дипломатии, которую можно определить как «ведение международных отношений посредством переговоров; метод, при помощи которого эти отношения регулируются и ведутся послами и посланниками; работа или искусство дипломата» ${ }^{3}$.

С наступлением информационного века на смену традиционной дипломатии пришла публичная или, как ее еще называют, общественная дипломатия. Впервые этот термин был введен в 1965 году Эдмундом Галлионом (Edmund Gullion) ${ }^{4}$, деканом Флетчерской Школы права и дипломатии Университета им. Тафтса. Публичная дипломатия имеет дело с влиянием, которое оказывает общественное мнение на формирование и осуществление внешней политики государства 5 .

\footnotetext{
3 Никольсон Г. Дипломатия / Пер. с англ. яз., под ред. и с предисловием А.А. Трояновского. М.: ОГИЗ, 1941. 1 с. - Режим доступа: http://scilib.narod.ru/Other/Nickolson/Diplomacy.htm

4 Cull N.J. 'Public Diplomacy' before Gullion: The Evolution of a Phrase / N.J. Cull. — USC Center on Public Diplomacy. - University of Southern California. 2006. 18 Apr.. - Режим доступа: http://uscpublicdiplomacy.org/index.php/newsroom/pdblog_detail/060418_public_diplomacy_before_gullion_the_evolution of_a_phrase._- Загл. с экрана.

5 What is Public Diplomacy? [Electronic resource] / The Edward R. Murrow Center of Public Diplomacy, The Fletcher School. -
} 
Публичная дипломатия возникла в силу нескольких взаимосвязанных причин: глобализации, развития коммуникационных технологий, а также ввиду усиления роли и участия обществ в международных делах государств.

Акторами публичной дипломатии теперь являются не только, собственно, государства и дипломаты, но и отдельные лица, группы, институты, участвующие в межкультурном, межкоммуникационном обмене, который оказывает влияние на международные отношения в рамках отношений двух или более государств.

Некоторые российские специалисты в области дипломатии определяют публичную дипломатию как один из типов дипломатии. Однако западные эксперты склоняются к тому, что публичная дипломатия это нынешний этап дипломатии, наступление которого было вызвано возросшим влиянием общественного мнения на внешнеполитические и внешнеэкономические инициативы государств.

Институт публичной дипломатии выстраивает отношения с общественностью, для большей эффективности, выделяя лидеров общественного мнения, экспертов, которые в последующем транслируют свою точку зрения в широкие массы.

На данном этапе времени на Западе уже широко исользуются приемы «новой публичной диломатии». Пентагон и Госдепартамент США уже имеют в своем штате сотрудников, специалистов по социальным медиа (или блоггеров, как их принято называть), которые устанавливают и регулярно поддерживают контакты с зарубежной аудиторией на ее родном языке и на привычных для нее коммуникационных и социальных площадках. Таким образом, дипломатии в XXI веке не достаточно оперативно передавать информацию и получать от общества обратную реакцию (что было свойственно для начального термина «публичная дипломатия»), а ей необходимо постоянно находиться в одном информационном поле со своими целевыми аудиториями, регулярно коммуницируя и взаимодействуя с ними.

По Дж.С. Наю мл. существует три измерения (или этапа) новой публичной дипломатии, каждое из которых имеет равное значение. Первое измерение и самое «неотложное» - ежедневные коммуникации, разъясняющие инициативы во внутренней и внешней политике государства. В этот же блок Джозеф Най относит и кризисные коммуникации, требующие молниеносной реакции, ввиду того, что информационный вакуум в наши дни практически невозможен, и он

Tufts University, USA. - Режим доступа: http://fletcher.tufts. edu/murrow/public-diplomacy.html. — Загл. с экрана. обязательно будет заполнен если не вами, то вашими соперниками.

Второй этап публичной дипломатии составляет стратегическая коммуникация, рассчитанная на более долгосрочную перспективу (недели, месяцы, года) нежели первая, которая измеряется минутами, часами и днями. Такой вид коммуникации предполагает разработку и продвижение набора простых тем и информационных тезисных сообщений, которые работают в пользу государства - прием широко используемый в рекламе и политике. Третье же измерение публичной дипломатии заключается в установлении и развитии долгосрочных отношений с ключевыми целевыми группами и лицами на протяжении нескольких лет или даже десятилетий с помощью программ обмена, предоставления стипендий, проведения мастер-классов, семинаров, конференций и т.д., всего того, что позволяет установить личный контакт, доверие и лояльность между людьми.

Коллега Дж.С. Ная, британский ученый Марк Леонард делит публичную дипломатию по принципу сотрудничество-конкуренция, выдвигая тезис о том, что государства на международной арене для улучшения собственного имиджа не только взаимодействуют сообща в разрешении глобальных или региональных проблем, но и играют по правилам «рынка», конкурируя между собой за внешнюю аудиторию и выдвигая тезисы, прямо констатирующие их конкурентные преимущества по сравнению с другими странами. Данная научная концепция, предложенная М. Леонардом, действительно, отражает реальную картину мира. Соединенные Штаты Америки, к примеру, видят ряд опасных конкурентов: в лице экстремистов, Китая, ведущего активную внешнеполитическую пропаганду на современном этапе; Европейского Союза, Австралии и Сингапура, продвигающих свои образовательные программы как альтернативу американским; и России, усилевшей в последнее время свое влияние на постсоветском пространстве, а также Ирана, укрепившего свои политические связи и культурное взаимодействие с миром.

Следует отметить, что «новая публичная дипломатия» является новой не в силу того, что отрицает все предыдущее, а наоборот наращивает и расширяет все технологии и методы дипломатии.

Другой известный ученый, занимающийся проблемами публичной дипломатии, Я. Мелиссен отмечает, что появление новой публичной дипломатии свидетельствует об усилении роли «мягкой силы» в международных отношениях и качественных изменениях в современной дипломатии как таковой ${ }^{6}$. Инновационным

6 Melissen J. The New Public Diplomacy: Soft Power in Inter- 


\section{Международные отношения International Relations}

для новой дипломатии, как представляется Р. Куперу, явялется ее стремление к прозрачности и транснациональному сотрудничеству ${ }^{7}$

Новая публичная дипломатия нацелена на работу, прежде всего, с гражданским обществом и общественным мнением, влияние которых усиливается в мире, ярким свидетельством чему стала знаменитая «арабская весна», ставшая уже не просто весной, а всеми временами года. И как показывает практика, влияние общества увеличивается не только в демократических странах, где есть гражданское общество, но и даже в странах с авторитарными правящими режимами.

Следует подчеркнуть, что «новая публичная дипломатия» — это не чисто академическая разработка. В США Департамент Заместителя Государственного секретаря по публичной дипломатии и связям с общественностью в 2010 году подготовил документ под названием «Глобальный стратегический план для новой публичной дипломатии в XXI веке/ Публичная дипломатия: усиливая взаимодействие США с миром» ${ }^{8}$. Данный план, разработанный на государственном уровне, также отмечает качественные изменения, происходящие на современном этапе в дипломатии, геополитике и, в целом, мире: усиление роли «масс» и молодежи в обществе (45\% от мирового населения составляет молодое поколение до 25 лет), отсутствие у традиционной двусторонней дипломатии возможности охватить в ходе своих коммникаций всех игроков, задействованных в глобальном мире, изменение сущности коммуникации ввиду того, что информация стала быстро, легко и широкодоступной и т.д. Т.е. профильный американский департамент заявляет о необходимости привести свою дипломатию в соответствие с вызовами и тенденциями современности.

Публичная дипломатия приобрела популярность на Западе после террористических актов, произошедших 11 сентября 2001 года в США. С тех пор борьба с терроризмом стала одной из важнейших повесток дня в кооперационной публичной дипломати и остается ею и по сей день. Другими актуальными вопросами, формирующими основу для

national Relations (Studies in Diplomacy and International Relations) / J. Melissen. - Palgrave Macmillan, 2005.

7 Cooper R. The Breaking of Nations: Order and Chaos in the Twenty-First Century / R. Cooper. London. - Atlantic Books, 2003. P. 76.

8 US Office of the Under Secretary of State for Public Diplomacy and Public Affairs: Strengthening U.S. Engagement with the World / A strategic approach for the 21st century. - Режим доступа: http://mountainrunner.us/files/dos/PD_US_World_Engagement.pdf сотрудничества в рамках «новой публичной дипломатии», являются информационная и кибербезопасность. Таким образом, мы видим, что публичная дипломатия выносит на повестку дня наиболее злободневные глобльные проблемы человечества, которые необходимо разрешить. Но также необходимо подчеркнуть, что каждая страна сама определяет круг таких вопросов, прежде всего, исходя из целей и задач своей внешней политики. Соединенные Штаты Америки в качестве приоритета своей «новой публичной дипломатии» выделяют продвижение демократии и прав человека9

«Новая публичная дипломатия», как уже неоднократно отмечалось, является «продуктом» современности и в то же время с ней и ее реалиаями должна постоянно взаимодействовать. Данное обстоятельство предполагает овладевание новыми навыками и технолгиями, ранее не применявшимися в традиционной дипломатии. В связи с этим автору представляется, что при подготовке специалистов нового поколения необходимо ввести дисциплины, раскрывающие сущность современной коммуникации, приемов маркетинга, а также новых технологий.

\section{Новые «имиджевые» коммуникационные технологии в работе Министерства иностранных дел}

Следует подчеркнуть, что Министерство движется в ногу со временем, учитывая все вызовы современного информационного века. Помимо информации, представленной на сайте МИДа, которая отличается всеобъемлющим характером, Министерство с 29 июня 2011 года ведет также микроблог в сети Твиттер, где публикаются краткие, но емкие тезисные сообщения, касающиеся внешнеполитического курса России. Аккаунт представлен на русском (MID_RF) и английском (MFA_Russia) языках. Официальный twitter-аккаунт Министерства иностранных дел Российской Федерации - это и есть новая публичная дипломатия, о которой пишет в своих работах Джозеф С. Най. Новая публичная дипломатия предполагает не просто одностороннюю передачу информации, а ведение диалога. Тенденция такова, что люди в современном обществе сами все меньше ищут информацию, так как ее чрезмерно много. Специалисты в области коммуникаций борются за каждого адресата, и сейчас информация настигает нужного человека сама. Поэтому для того, чтобы добиться внимания нужной целевой аудитории, необходимо осваивать и пространство социальных сетей, которое все большее количество лю-

\footnotetext{
9 Там же.
} 
дей использует в качестве площадки для передачи и обмена информацией. О качественно новой тенденции активного влияния информационно-коммуникационных технологий на международные процессы писал В.В. Путин в вышеупомнятутой статье: «...мировое общественное мнение в нынешнее время формируется путем самого активного задействования продвинутых информационных и коммуникационных технологий. Можно сказать, что интернет, социальные сети, мобильные телефоны и т.п. превратились - наряду с телевидением - в эффективный инструмент как внутренней, так и международной политики» ${ }^{10}$.

Твиттер - это не просто модная тенденция в сфере социальных сетей, это ресурс, который в огромном информационном потоке может оперативно выдавать актуальную, нужную, своеврменную, емкую и краткую информацию. В МИД России надеются на то, что новый ресурс будет рассчитан на широкую аудиторию и особенно полезен находящимся за рубежом россиянам. Так, например, подписчики смогут получать информацию на мобильные телефоны и коммуникаторы в случае оповещения о чрезвычайных ситуациях в стране нахождения ${ }^{11}$.

Профиль в информационной сети довольно активно ведет также заместитель министра иностранных дел Г.М. Гатилов. Количество его читателей составляет 1,091 человек.

Страница российского загранучреждения в Интернете - уже сложившаяся норма. Однако, стоит отметить, что российские посольства пока не в полной мере исользуют новые коммуникационные технологии. Об этом в ходе своей встречи с сотрудниками МИД говорил Д.А. Медведев: «Идти в ногу со временем крайне необходимо. Это касается не только центрального аппарата Министерства, который сейчас уже этим занимается, но и даже в большей степени наших посольств и других наших загранучреждений. Собственно, вы сами это отлично знаете, потому что именно по их деятельности судят и о России, и о том, насколько дружелюбной является наша внешняя политика» ${ }^{12}$.

10 Путин В.В. Россия и меняющийся мир / В.В. Путин // Политика. Портал газеты «Московские новости». 2012. 27 фев. Режим доступа: http://mn.ru/politics/20120227/312306749.html. Загл. с экрана.

11 Макарычев М. МИД выходит в «Твит». На Смоленской площади создали записи в социальной сети / М. Макарычев // Российская газета. 2011. 30 июн. №5515 (139) // Сайт Российской газеты. - Режим доступа: http://www.rg.ru/2011/06/30/ mid-tvitter.html. - Загл. с экрана.

12 Дмитрий Медведев провёл встречу с сотрудниками Министерства иностранных дел накануне профессионального праздника - Дня дипломатического работника // Официальный сайт
B социальной сети Фейсбук (Facebook) всего три российских посольства имеют собственную страницу (Посольства России в Македонии, Бельгии и Турции) и лишь два (за исклюением Посольства в Турции) активно обновляют информацию на них. Русскоязычный аналог фейсбука «Вконтакте» пользуется большей популярностью среди российских посольств (по популярности: Посольства России в США, Китае, Австрии, Финляндии, Индонезии, Дании, на Кубе, Финляндии, Ирландии, Австралии, Польше и Алжире), хотя, если сравнивать две социальные сети «vk.com» и «facebook», то «имиджевая» эффективность последней больше ввиду ее международного характера и большего охвата (901 миллион активных пользователей против 120 миллионов пользователей российского аналога).

Ведение микроблога в режиме реального времени в информационной сети твиттер представителем российского посольства за рубежом (пресс-атташе) может стать первым шагом на пути модернизации информационных технологий. Кто-то может посчитать, что твиттер - это лишь дань моде и эфемерный вид коммуникации. Однако именно ведение микроблога позволит довольно большому числу заинтересованных лиц получать ясную, краткую и незамедлительную информацию от посольства: анонс важных мероприятий, комментарии официальных лиц по тому или иному вопросу и т.д.

По состоянию на 7 июня 201 года в информационной сети твиттер (twitter.com) существовали следующие профили российских посольств (по числу читателей в порядке убывания): в Великобритании (2,595 читателя), Греции (842), Бразилии (670), Нигерии (443), Бельгии (442), Польше (427), Индонезии (332), Гане (308 на двух языках), Дании (287), Португалии (282 - на двух языках), Шри-Ланке и Мальдивской Республике (255), Алжире (250), Люксембурге (247), Белоруссии (174), Ирландии (172), Аргентине (127), Афганистане (122), Израиле (112), Италии (103), Словении (100), Франции (97), Испании (97), Бургунди (84), Сингапуре (68), Сербии (62), Мадагскаре (58), Канаде (49), Тайланде (34), Брунее (4). Однако активные обновления профиля в режиме реального времени производят меньше трети (Великобритания, Индонезия, Италия, Бельгия, Шри-Ланка и Мальдивская Ресупблика, Люксембурге, Словения, Греция). Многие посольства из списка вообще не пишут твитты месяцами или не имеют ниодной записи (Посольство России в Аргентине, Афганистане, на Мадагаскаре, Франции, Сербии), тем самым эффективность ведения микро-

МИД России. — Режим доступа : http://www.mid.ru/brp_4.nsf/0/ C878E186E254440A4425799F00585897. — Загл. с экрана. 


\section{Международные отношения International Relations}

блога сводится к нуллю. В то время как, к примеру, американские посольства обновляют информацию чуть ли не ежечасно.

У современных коммуникационных технологий имеются свои недостатки. Однако в настоящее время государству без них не обойтись, если оно хочет проводить успешную информационную политику: «Здесь не надо стесняться, скажем, того, что не хватает глубины иногда в тех или иных социальных сетях или же бесконечный поток всякого рода злоупотреблений словесным жанром и просто иногда прямых оскорблений. Всё равно нужно настойчиво проводить нашу линию, собственно, так же, как это и делают, ещё раз подчёркиваю, наши коллеги в других странах» ${ }^{13}$.

Соединенные Штаты Америки являются одной из самых прогрессивных стран в сфере использования новых коммуникационных технологий. Бывший посол США в России Джон Байерли, находясь на службе в Москве, вел живой журнал в русскоязычной блогосфере и рассказывал о наиболее значимых событиях в российско-американских отношениях. А нынешний посол США в России Майкл Макфол активно ведет не только живой журнал (http://m-mcfaul.livejournal. com/), но и аккаунт в твиттере, разве что не ежеминутно обновляя информацию. Число читателей его микроблога по состоянию на 7 июня 2012 года составило 26,879 человек.
Что касается консульств России и новых коммуникационных технологий, то, к примеру, в информационной сети твиттер пять генеральных консульств России имеют профили: Генеральное консульство в Карачи (Пакистан), Кейптауне (ЮАР), Мюнхене (ФРГ), Сан-Франциско (США), Франкфурте (ФРГ). Однако стоит отметить, что только один профиль (Генерального консульства в Карачи) активен, а остальные либо очень редко обновляют информацию либо не ведут микроблог вовсе.

Постпредства при ООН, ООН и других международных организациях в Женеве, а также при НАТО имеют официальные профили в твиттере. Однако ни один из них не был активен к 7 июня 2012 года, хотя аккаунт постоянного представительства при НАТО насчитывал 14,158 читателей.

Таким образом, новая публичная дипломатия публичная дипломатия не должна быть «падчерицей» российских дипломатов, каковой она в свое время приходилась по мнению журналиста Дэвид Хоффмана (David Hoffman) американской дипломатии ${ }^{14}$. Она просто не имеет права быть таковой в XXI веке. Российским дипломатам необходимо с полным осознанием и пониманием подходить к использованию новых коммуникационных технологий на современном этапе для того, чтобы заручиться поддержкой широкой общественности, без которой сегодняшняя дипломатия неэффективна.

\section{Список литературы:}

1. Дмитрий Медведев провёл встречу с сотрудниками Министерства иностранных дел накануне профессионального праздника - Дня дипломатического работника // Официальный сайт МИД России. — Режим доступа : http://www.mid.ru/brp_4.nsf/0/C878E186E254440A4425799F00585897. — Загл. с экрана.

2. US Office of the Under Secretary of State for Public Diplomacy and Public Affairs: Strengthening U.S. Engagement with the World / A strategic approach for the 21st century. — Режим доступа: http://mountainrunner.us/files/dos/ PD_US_World_Engagement.pdf

3. Никольсон Г. Дипломатия / Пер. с англ. яз., под ред. и с предисловием А.А. Трояновского. М.: ОГИ3, 1941. 1 c. - Режим доступа: http://scilib.narod.ru/Other/Nickolson/Diplomacy.htm

4. Cull N.J. 'Public Diplomacy' before Gullion: The Evolution of a Phrase / N.J. Cull. — USC Center on Public Diplomacy. - University of Southern California. 2006. 18 Apr. - Режим доступа : http://uscpublicdiplomacy. org/index.php/newsroom/pdblog_detail/060418_public_diplomacy_before_gullion_the_evolution_of_a_phrase. _ Загл. с экрана.

5. Cooper R. The Breaking of Nations: Order and Chaos in the Twenty-First Century / R. Cooper. London. Atlantic Books, 2003.

6. Leonard M. Public Diplomacy / M. Leonard, C. Stead, C. Smewing. London, Foreign Policy Centre, 2002.

7. Melissen J. The New Public Diplomacy: Soft Power in International Relations (Studies in Diplomacy and International Relations) / J. Melissen. - Palgrave Macmillan, 2005.

8. Miles J. Toward a New Public Diplomacy — Redirecting U.S. Foreign Policy / Ed. Philip Seib. — Palgrave MacMillan, New York. 2009.

13 Там же.
14 Hoffman D. Beyond Public Diplomacy [Electronic resource] / D. Hoffman // Forreign Affairs. № 81. — University of Leeds, UK, March April 2002. - Режим доступа: http://ics.leeds.ac.uk/papers/ vp01.cfm?outfit=pmt\&folder=7\&paper=456. - Загл. с экрана. 
9. Nye J.S.Jr. Soft Power: The Means To Success In World Politics / J.S. Nye. — PublicAffairs, 2005.

10. Макарычев М. МИД выходит в «Твит». На Смоленской площади создали записи в социальной сети / М. Макарычев // Российская газета. 2011. 30 июн. №5515 (139) // Сайт Российской газеты. - Режим доступа: http://www.rg.ru/2011/06/30/mid-tvitter.html. — Загл. с экрана.

11. Путин В.В. Россия и меняющийся мир / В.В. Путин // Политика. Портал газеты «Московские новости». 2012. 27 фев. — Режим доступа: http://mn.ru/politics/20120227/312306749.html. — Загл. с экрана.

12. Hoffman D. Beyond Public Diplomacy [Electronic resource] / D. Hoffman // Forreign Affairs. № 81. - University of Leeds, UK, March April 2002. — Режим доступа: http://ics.leeds.ac.uk/papers/vp01.cfm?outfit=pmt\&folder=7\& paper=456. - Загл. с экрана.

13. Nye J.S. New Public Diplomacy [Electronic resource] / J.S. Nye. — Project Syndicate: a World of Ideas. Cambridge, 2010. — Режим доступа: http://www.project-syndicate.org/commentary/nye79/Russian. — Загл. с экрана.

14. What is Public Diplomacy? [Electronic resource] / The Edward R. Murrow Center of Public Diplomacy, The Fletcher School. — Tufts University, USA. — Режим доступа : http://fletcher.tufts.edu/murrow/public-diplomacy.html. Загл. с экрана. 